\title{
DIGITALCOMMONS
}

@WAYNESTATE -

Wayne State University

9-24-2019

\section{How the Atacama Skeleton Might Advance Discussion of Responsible Conduct of Research Responsibilities}

Thomas May

Elson S. Floyd College of Medicine, Washington State University Vancouver, Vancouver, Washington, USA, thomas.may@wsu.edu

Mariko Nakano-Okuno

School of Medicine, University of Alabama at Birmingham, Birmingham, Alabama, USA

\section{Recommended Citation}

May, Thomas and Nakano-Okuno, Mariko, "How the Atacama Skeleton Might Advance Discussion of Responsible Conduct of Research Responsibilities" (2019). Human Biology Open Access Pre-Prints. 150.

https://digitalcommons.wayne.edu/humbiol_preprints/150 


\title{
How the Atacama Skeleton Might Advance Discussion of Responsible Conduct of Research Responsibilities
}

Thomas May ${ }^{1 *}$ and Mariko Nakano-Okuno ${ }^{2}$

${ }^{1}$ Elson S. Floyd College of Medicine, Washington State University Vancouver, Vancouver, Washington, USA.

${ }^{2}$ School of Medicine, University of Alabama at Birmingham, Birmingham, Alabama, USA. *Correspondence to: Thomas May, Elson S. Floyd College of Medicine, Washington State University Vancouver, 14204 NE Salmon Creek Ave., Vancouver, WA 98686 USA. E-mail: thomas.may@wsu.edu.

Short Title: The Atacama Skeleton and Responsible Conduct of Research

KEY WORDS: ETHICS, RESPONSIBLE CONDUCT OF RESEARCH

\begin{abstract}
Controversies resulting from genetic testing on skeletal remains of disputed stewardship raise important questions about obligations inherent on genetic researchers to assure ethical chain of custody. In this paper, we analyze and evaluate several proposed positions on whether such research should be published. Following jurisprudential standards for legitimate regulatory systems, we argue that responsible conduct of research requires reasonable attention to chain of custody, but cannot require guarantees, particularly in cases of ancient remains.
\end{abstract}

Pre-print version. Visit http://digitalcommons.wayne.edu/humbiol/ after publication to acquire the final version. 
The recent controversy surrounding research by Bhattacharya et al (2018) on the skeletal remains of what turned out to be a human fetus of Chilean descent has clouded several important issues in the responsible conduct of research. A focus on the issue of whether the study qualified as human subjects research has obscured the more fundamental issue of the ethical conduct of scientific research in general, and the duties of researchers to proactively assure ethical chain of custody for samples. This, in turn, has distracted from the authors' valid response to these ongoing controversies in terms of reasonable beliefs that the skeletal remains tested did not warrant ethical concerns. While such response will not (and probably should not) resolve the most controversial aspects of this debate, it should be respected as a valid position worthy of furthering a fundamental on-going debate in the responsible conduct of research: the scope of duties to assure the lack of potential ethical problems within a research project.

The most salient elements of this controversy surround the conduct of studies on skeletal remains for which researchers had not been granted permission by the remains' "proper steward," which is identified by critics as the Chilean Government. The mummified skeleton was originally found near a church in the abandoned Chilean town of La Noria, and acquired by an individual living in Spain who granted access to the mummy to a UFOlogist filmmaking crew who claimed the mummy was likely of alien origin. This attracted the attention of Stanford researcher Garry Nolan, who then conducted a pair of studies on samples from the remains in 2013 and 2018, the latter of which was published in Genome Research. The subsequent controversies are due to valid Chilean sensitivities to "the looting and smuggling of artifacts," a concern whose validity is recognized in a published response by Nolan and Butte, who have called for the return of the remains to Chile. This point seems straightforward and unworthy of controversy per se: neither researchers, journal editors, critics nor government officials dispute 
the ethical duty to return the remains to Chile; although it is unclear from published reports exactly where the individuals currently in possession of the remains - Nolan and Butte are clear they have never been in possession of more than small samples from the remains - stand; nor have these individuals' claims to ownership been publicly assessed. These issues, however, are legal disputes about the scope and limits of property rights and individual acquisition of properties that are of value to a broader society, rather than scientific misconduct.

Where the scientific controversy arises concerns the scope of duties inherent on scientific researchers to assure that the objects of research are ethically valid subjects, be they human, nonhuman or inanimate. It is here that the debate over the recent Genome Research article has become clouded: while critics argue that the research in question is tainted and therefore should not be published, proponents have obscured valid arguments concerning the practical limits to potential duties of ethical assurance, with technical (perhaps legal or regulatory motivated?) arguments about whether this research qualified as "human subjects research" under federal definitions. (Sussman, 2018) Such arguments miss the fundamental concerns of critics, whose objections do not revolve around technical adherence to federal definitions.

One approach articulated by critics in comments on the website "Gizmodo" surrounds the argument that unethical research is scientifically invalid as a matter of fact, and as invalid research should not be published. The problem with this approach is that at least in the present case, its appeal is dependent on the acceptance of (at least) two philosophical fallacies: the fallacy of equivocation; and of ad hominem argumentation. The former is reflected by critics' equivocation on the normative (il)legitimacy of the research with the descriptive (il)legitimacy of the application of scientific methodology: two very different objects of assessment. The latter fallacy (ad hominem) relies on the normative (moral) repugnance of an individual or act to 
establish a descriptive (empirical, factual) invalidity which is independent of the normative evaluation of the individual or act. Bad people can make factually accurate statements, and valid scientific methodologies might be applied to objects for which our moral sensibilities would discourage application. In short, whether or not a particular study should be conducted is a different issue than whether it might factually be studied in accord with valid empirical methodologies.

Valid arguments that ethically tainted research should not be published can take one of (at least) two foundational approaches, which mimic jurisprudential debates about the purpose of punishment: sanctions (in this case, refusal to publish) can be designed as retributive for unethical conduct; or can be designed to provide incentives for ethical behavior (or disincentives for unethical behavior). Each of these require what is in law known as "mens rea" (a "guilty mind"), or intent, to act in an unethical manner. In the case of retribution, it makes no sense to punish behavior that does not reflect intentional control, as such behavior is not subject to praise or blame (May, 1994). In the case of incentives, to shape behavior through incentives, the behavior must be intentional (or at least be able to be intentional, as in the case of disincentivizing negligence), as one cannot "shape", for example, a reflex behavior not controllable by the subject. Key to this approach is for what legal scholars have dubbed "rules of recognition," most famously articulated by H.L.A. Hart in his classic work, The Concept of Law. (Hart, 1961; Kelsen, 1967; Raz, 1970) Hart explains that in order for regulations to effectively serve their purpose in guiding human behavior, they must avoid vagueness, and be sufficiently recognizable as applicable to a particular circumstance so as to be able to guide behavior. As part of this, the burdens of interpretation and application cannot become so great as to undermine the regulatory system's ability to communicate requirements that are understood and applicable. 
Failure to adequately communicate recognizable guidance applicable to particular circumstances constitutes a "pathology" that can undermine the legitimacy of a regulatory system. (Spellecy and May, 2012).

For ancient remains in particular (where generations have passed between custody of land, remains etc.,) to require absolute certainty concerning lack of chain of custody challenges or problems would threaten adherence to reasonable "rules of recognition." Nolan and Butte's explanation that reports on the mummy in question were public knowledge for 15 years prior to their studies, with no concerns raised by the Chilean government, seems a plausible basis for not suspecting ethical objection. This provides strong prima facie reason to believe there were no obvious ethical problems with the samples in terms of illegitimate acquisition, and thus no intentional breach of ethical duty. Still, critics could argue that morality might require more in cases like these than lack of obvious ethical problems. Indeed, a case might be made that 'lack of obvious ethical problems' is a rather low bar for something as serious as our duties not to conduct unethical scientific research: greater positive concern to assure ethics should be expected. While a retributive approach could capture this through sanction of negligence, again, the lack of Chilean government objection for 15 years makes a case for negligence seem spurious.

A case for higher ethical expectations would be strongest in the context of incentives to take seriously ethical duties to assure lack of immoral activities. Here, the weakness of Nolan and Butte's defense (Nolan and Butte, 2018) that it was not known that the remains was of human origin is clear if one takes seriously the idea that human subjects research protections are important enough that even suspected human research should be subject to review. The statement issued by the Chilean Society of Biological Anthropology captures this sentiment well: 
"Could you imagine the same study carried out using the corpse of someone's miscarried baby in Europe or America?" (Dvorsky, 2018).

However, while we may wish for higher standards than "lack of obvious ethical problems," we cannot require omniscience of scientific researchers. In this, we must allow researchers to drawn reasonable inferences about ethical appropriateness if disincentives are not to become paralyzing. The unknowns surrounding the remains in question, the prima facie lack of reason to believe there were ethical problems with how samples were obtained, and anonymity of both the skeleton and its suspected age (Zimmer, 2018) all undermine the potential effectiveness of sanctions employed as (dis)incentives if we do not wish such disincentives to discourage scientific research altogether. The legitimacy of publishing the study by Bhattacharya et al seems strong, then, in this particular context. However, the more fundamental issue of what positive duties researchers have to assure moral acceptability of samples remains, and must be addressed by the scientific community as well as society at large.

Here, the field and scientific community in general could benefit from greater attention to principles of community engagement that are gaining recognition throughout the biomedical sciences. Rather than punitive, these principles are offered as methods for optimizing benefits from biomedical research by helping to align specific cultural and community values with the aims of scientific research. Indeed, community engagement is consistent with recommendations from within the paleogenomics community concerning the conduct of research on indigenous remains.

In recent literature (Claw et al. 2017; Bardill et al. 2018), indigenous scientists and allies have highlighted the need for clearer ethical guidelines on archeogenomic studies on local human remains, which should include strong requirement for consultation and collaborative 
relationships with tribal, or (when the remains are culturally unidentified) geographically proximate, communities. Without such consultation and collaborations, they claim, research may lead to indiscrete study design and utilize culturally-insensitive descriptions in the report of findings, which can make negative impacts on the integrity of indigenous communities that are "intimately connected with the land where they reside, caring for both the land and ancestors held within, even if they are not direct biological descendants" (Bardrill, et al., 2018).

This ethical requirement to involve local communities in archeological studies is not new, and needs not be limited to the studies on human remains. UNESCO's 1956 Recommendation on International Principles applicable to Archaeological Excavations indicates that, while "all archaeological remains" of public value should be studied and the results be published to further our knowledge, foreign researchers (or their institutions) should first consult with, and obtain excavation concession by, the nation in which the remains are found, due to "the respect and affection felt for them [the studied remains] by the people themselves" (UNESCO 1956). Considering these recent proposals and past recommendations, it would have been ethically more desirable had the genetic researchers in the Atacama Skeleton study proactively communicated with the Chilean government and/or the indigenous community where the skeleton was originally found before they initiated the genomic analysis of the skeleton, be it human, nonhuman, or potentially of an extraterrestrial origin.

The value of engaging communities offers protections from unintentional harms that are not envisioned by those not members of the community in question. For example, greater attention to community engagement is often cited as a way to avoid unexpected objections and harms like those associated with the Havasuppai Tribe genetic research conducted by Arizona State University (Mello and Wolf, 2010). The past decades have seen a specialized field develop 
in this arena, complete with journals documenting effective methods and lessons learned. Such engagement not only offers protections from harms to engaged community, but also fosters trust and commitment to the biomedical research enterprise as a whole.

Received 28 February 2019; accepted for publication 9 July 2019. 


\section{Literature Cited}

Bardill, J., A. C. Bader, N. A. Garrison et al. 2018. Advancing the ethics of paleogenomics: Ancestral remains should be regarded not as 'artifacts' but as human relatives who deserve respect. Science 360:384-385.

Bhattacharya, S., J. Li, A. Sockell et al. 2018. Whole-genome sequencing of Atacama skeleton shows novel mutations linked with dysplasia. Genome Res. 28:423-431.

Claw, K. G., D. Lippert, J. Bardill et al. 2017. Chaco Canyon dig unearths ethical concerns. Hum. Biol. 89:177-180.

Dvorsky, G. 2018. Chile is seriously pissed about the 'alien’ mummy study. Gizmodo, March 29. https://gizmodo.com/chile-is-seriously-pissed-about-the-alien-mummy-study1824177937.

Hart, H. L. A. 1961. The Concept of Law. Oxford: Oxford University Press.

Kelsen, H. 1967. Pure Theory of Law. Berkeley, CA: University of California Press.

May, T. 1994. The concept of autonomy. Am. Philos. Q. 31:133-144.

Mello, M., and L. Wolf. 2010. The Havasupai Indian tribe case: Lessons for research involving stored biologic samples. N. Engl. J. Med. 363:204-207.

Nolan, G., and A. Butte. 2018. The Atacama skeleton. Genome Res. 28:607-608.

Raz, J. 1970. The Concept of a Legal System. Oxford: Clarendon Press.

Spellecy, R., and T. May. 2012. More than cheating: Deception, IRB shopping, and the normative legitimacy of IRBs. J. Law Med. Ethics 40:990-996.

Sussman, H. 2018. A statement about the publication describing genome sequencing of the Atacama skeleton. Genome Res. 28:xiv.

Pre-print version. Visit http://digitalcommons.wayne.edu/humbiol/ after publication to acquire the final version. 
United Nations Educational, Scientific and Cultural Organization. 1956. Recommendation on International Principles Applicable to Archaeological Excavations. http://portal.unesco.org/en/ev.phpURL_ID=13062\&URL_DO=DO_TOPIC\&URL_SECTION=201.html.

Zimmer, C. 2018. Was a tiny mummy in the Atacama an Alien? No, but the real story is almost as strange. The New York Times, March 22. https://www.nytimes.com/2018/03/22/science/ata-mummy-alien-chile.html. 